\title{
Monitoring Suhu Ruang Budidaya Jamur Tiram Menggunakan Android Berbasis Arduino
}

\author{
Ul Khairat ${ }^{1}$ \\ Basri $^{2}$ \\ Wira Azmi Fakhrurrozi ${ }^{3}$
}

Teknik Informatika, Fakultas Ilmu Komputer, Universitas Al Asyariah Mandar

Madatte, Polewali, Polewali Mandar, Indonesia

E-mail: $\underline{\text { ul.khairat24@gmail.com }}{ }^{1}{ }^{\text {; basri.birsal@gmail.com }}{ }^{2}$; wiraazmi1997@gmail.com $^{\text {z }}$

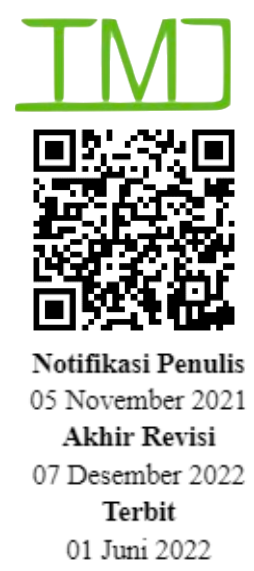

Khairat, U., Basri, B., \& Fakhrurrozi, W. A. (2022). Monitoring Suhu Ruang Budidaya Jamur Tiram Menggunakan Android Berbasis Arduino. Technomedia Journal, 7(1 Juni), 110.

https://doi.org/10.33050/tmi.v7i1.1762

\begin{abstract}
ABSTRAK
Monitoring suhu ruang sampai hari ini masih banyak dilakukan dengan cara manual sehingga kegiatan ini membuat waktu kerja tidak begitu efektif, maka dari itu sebagai solusi dari permasalahan yang ada penulis berusaha menciptakan sebuah sistem monitoring yang terintegritas smartphone sehingga proses monitoring dapat dilakukan dari jarak jauh sekalipun. Sistem tersebut berbasis Arduino yang sudah terintegras dengan Firebase. Sistem ini menggunakan sensor suhu DHT11 dan NodeMCU ESP8266 sebagai pemroses data serta pengirim informasi ke smartphone pemonitor, sehingga proses monitoring pun tak perlu lagi dilakukan dengan cara manual.
\end{abstract}

Kata kunci : Monitoring, Suhu, Android, Arduino

\section{ABSTRACT}

The monitorng of space temperature today is sometimes done by hand so that the activity makes work time less effective, hence as the solution to the problem the writer is trying to create an integrity monitoring system so that the monitoring process can be done remotely. It's an Arduino based system that's already integrity to Firebase. The system uses the DHT11 and NodeMCU ESP8266 temperatute sensors as a data processor and transmits information to smartphone, so that monitoring processes are no longer required by hand.

Keywords: Monitoring, Temperature, Android, Arduino 


\section{PENDAHULUAN}

Jamur Tiram Polman merupakan sebuah rumah budidaya jamur tiram yang dijalankan secara swadaya oleh beberapa pemuda di dusun Lemo Tua desa Kuajang sebagai UMKM (Usaha Mikro Kecil Menengah) di mana proses monitoring suhu ruang budidaya jamur pada tempat itu masih dilakukan manual secara berkala, tentunya hal tersebut membuat waktu kerja tidak optimal sehingga hasil panen pun selalu tidak sesuai dengan hasil yang ingin dicapai [1].

Di masa revolusi industri seperti sekarang dengan perkembangan teknologi yang kian pesat membantu segala pekerjaan kita menjadi lebih mudah begitupun dalam melakukan proses monitoring suhu ruangan, kini hanya dengan menggunakan perangkat gadget yang kita miliki pun proses monitoring dapat dilakukan dengan mudah tanpa perlu mengecek manual suhu ruang secara berkala [2]. Menggunakan Android sebagai media sehingga proses monitoring pun dapat dilakukan dengan mudah [3].

Sampai kini masih banyak ditemui proses monitoring suhu yang dilakukan dengan cara manual yaitu mendatangi setiap ruang, mengukur temperatur suhu dan mencatatnya [4]. Untuk mengatasi hal tersebut saya tertarik untuk membuat penelitian dengan judul "Monitoring Suhu Ruang Budidaya Jamur Tiram Menggunakan Android berbasis Arduino"

Monitoring adalah suatu langkah pengumpulan dan analisis informasi berdasarkan keterangan yang ditetapkan secara sistematis tentang suatu kegiatan atau program sehingga dapat dilakukan tindakan koreksi guna penyempurnaan kegiatan atau program itu selanjutnya [5]. Android adalah sebuah sistem operasi berbasis mobile yang menyediakan Application Programming Interface yang mampu menawarkan akses ke perangkat keras, data ponsel, serta data ke sistem sendiri [6]. Modul Node MCU merupakan firmware interaktif berbasis LUA Espresseif ESP8266 [7].

\section{PERMASALAHAN}

Permasalahan utama yang penulis temui adalah proses monitoring yang masih dilakukan dengan cara manual, di mana dari masalah yang ada itu membuat proses kerja tidak maksimal sebab kerentanan pertumbuhan jamur tiram terhadap suhu dan perubahan suhu yang kerap terjadi tiap saat membutuhkan perhatian khusus terutama pemantauan tiap saat [8]. Maka dari itu penulis mengusulkan satu rancangan sistem sebagai suatu solusi untuk permasalahan yang ada, di mana sistem monitoring yang ditawarkan dapat terhubung ke smartphone sehingga proses monitoring dapat dilakukan tiap saat dengan mudah meski dari jarak jauh sekalipun.

\section{METODOLOGI PENELITIAN}

Pada penelitian ini penulis menggunakan metode penelitian kualitatif yaitu dengan melakukan observasi, wawancara, dan tinjauan ke lokasi penelitian.

\subsection{Rancangan Penelitian}


a. Pada tahapan awal yang dilakukan adalah investigasi masalah, yaitu bagaimana proses monitoring suhu ruang budidaya jamur tiram.

b. Langkah ke dua yaitu mencari referensi dari jurnal, artikel atau penelitian terdahulu.

c. Langkah ke tiga yaitu merancang sebuah alah monitoring suhu ruang budidaya jamur tiram

d. Langkah ke empat yaitu melakukan revisi sistem yang telah dibuat berdasarkan hasil penelitian yang ada.

e. Hasil penelitian yang dilakukan berupa sistem monitoring suhu ruang budidaya jamur tiram dengan aplikasi android.

f. Tahap akhir kemudian membuat laporan akhir.

\subsection{Teknik Pengumpulan Data}

a. Studi Pustaka

Teknik pengumpulan data melalui studi pustaka ini adalah mengumpulkan data melalui jurnal penelitian yang telah ada untuk dijadikan bahan referensi dalam mendukung penulisan ini.

b. Penelitian Lapangan

Dalam hal ini, penelitian dilakukan di lapangan untuk memperoleh informasi serta data yang diperlukan. Adapun teknik yang ditempuh adalah:

a) Observasi

Penelitian dilakukan secara langsung pada objek yang diteliti, bertujuan untuk mendapatkan gambaran jelas tentang jamur tiram.

b) Wawancara

Melakukan dialog dengan beberapa pihak terkait pada suatu objek yang akan diteliti, dengan tujuan mendapat informasi penting mengenai data yang berkaitan dengan sistem yang dirancang.

\subsection{Teknik Analisis Data}

Data yang terkumpul melalui studi pustaka, penelitian lapangan (observasi dan wawancara) kemudian dikumpulkan dan dikategorikan kemudian dianalisa. Teknik analisis yang diterapkan agar bisa dengan mudah dalam merancang dan membangun sistem monitoring suhu ruang budidaya jamur tiram menggunakan android [9], [10].

\subsection{Literature Review}

a. Penelitian terkait yaitu "Rancang Bangun Sistem Monitoring Suhu Ruangan Bagian Pembukuan Berbasis Web Menggunakan Mikrokontroler Arduino Uno R3”. Sistem ini merupakan perpaduan perangkat keras dan juga perangkat lunak di mana keduanya saling terhubung dengan baik berdasarkan perintah untuk mendeteksi suhu ruangan. Perangkat keras terdiri dari Arduino Uno R3, sensor suhu LM35D untuk mendeteksi suhu ruangan. Perangkat lunak sistem terdapat di dua sisi, pertama di bagian papan mikrokontroler, merupakan sebuah program untuk 
menjalankan tindakan pemicu terhadap sensor suhu LM35D. Kemudian program kedua terdapat di bagian komputer server. Program pada komputer server merupakan kategori program berbasis web. Hal ini dilakukan karena sistem berjalam pada arsitektur jaringan komputer, dan media antar muka pengguna sistem adalah aplikasi browser [11].

b. Berdasarkan penelitian "Alat Pengatur Suhu Kelembaban Dan Monitoring Masa Panen Pada Budidaya Jamur Tiram Berbasis Arduino Uno”. Dapat disimpulkan bahwa Unjuk kerja dari Alat Pengatur Suhu Kelembaban dan Monitoring Masa Panen pada Budidaya Jamur Tiram Berbasis Arduino Uno secara keseluruhan bekerja dengan baik. Semua komponen dapat digunakan sebagaimana mestinya [12].

c. Penelitian terkait “ Perancangan Smart Monitoring System Pada Pembudidayaan Jamur Tiram Berbasis Pemograman Arduino dan Labview " dengan hasil Logging data pembacaan sensor bertipe file excel secara langsung dengan jumlah satu sampel selama lima detik. Dan data akan dikirimkan secara otomatis kepada Email pengguna [13].

d. Penelitian terkait " Rancang Bangun Alat Monitoring Suhu dan Kelembaban Pada Alat Baby Incubator Berbasis Internet Of Things" dan berdasarkan pada perencanaan juga hasil pengambilan data serta pengolahan data suhu matras, suhu incubator dan kelembaban ini yang akhirnya dapat ditarik kesimpulan bahwa Modul Rancang Bangun Alat Monitoring Suhu dan Kelembaban pada Alat Baby incubator Berbasis Internet Of Things ini sesuai dengan yang direncanakan [14].

\section{HASIL DAN PEMBAHASAN \\ Hasil Penelitian}

Adapun hasil dari penelitian yang telah dilakukan oleh penulis yaitu sebuah sistem monitoring suhu ruang berbasis arduino dengan menggunakan aplikasi smartphone. Dalam membangun program, penulis menggunakan bahasa pemograman $\mathrm{C}$ untuk perintah pada arduino dan bahasa pemograman Java untuk membangun aplikasi monitoring suhu ruang. Aplikasi menyediakan fitur yang berfungsi untuk membantu memperlihatkan suhu secara akurat melalui smartphone [15]. 


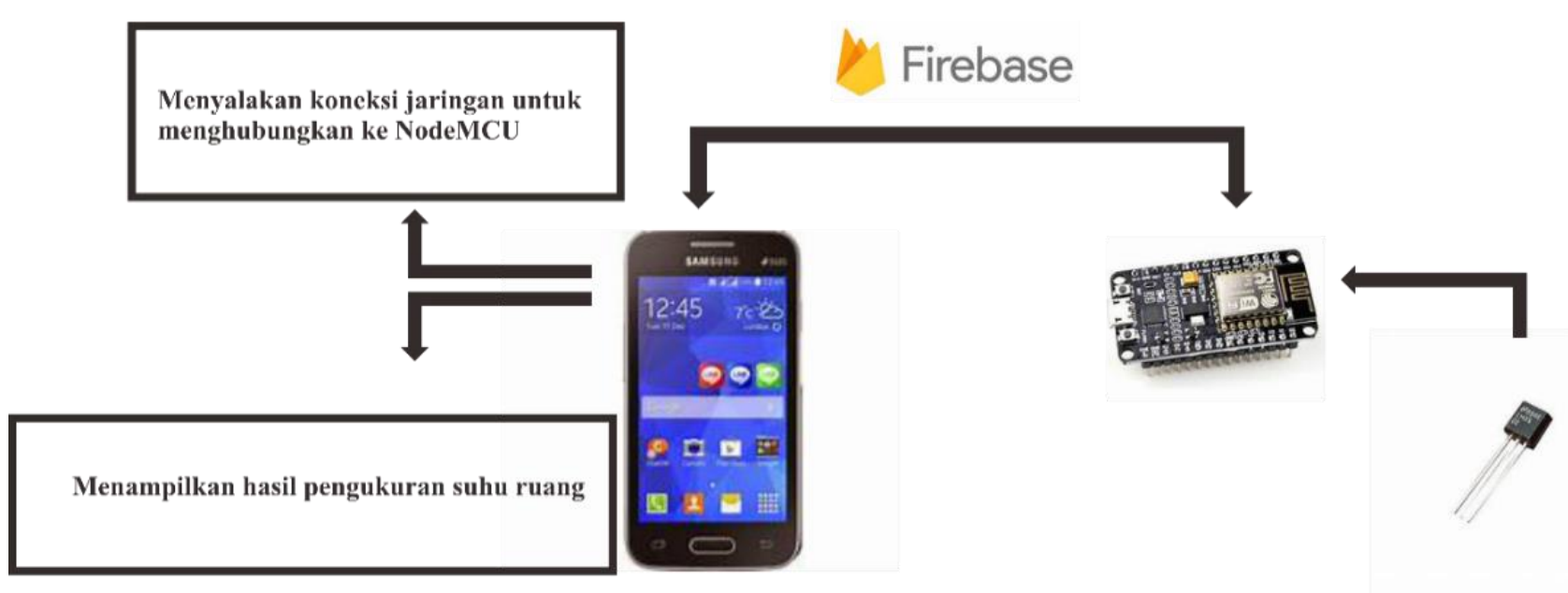

Gambar 1. Infrastruktur Sistem

\section{User Interface Program}

Berikut ini adalah beberapa tampilan sistem yang telah dibuat oleh peneliti:

a) Form Realtime Monitoring Suhu Ruang

Tampilan Aplikasi ini digunakan oleh pengguna untuk melihat temperatur suhu melalui smartphone seperti terlihat pada gambar 2

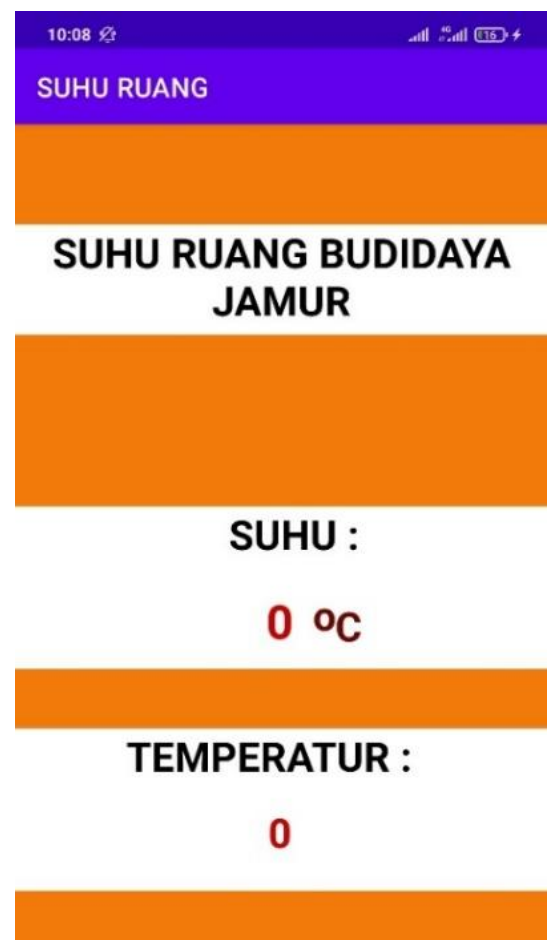

Gambar 2. Form Monitoring Suhu Ruang 
b) Rangkaian Arduino

Berikut adalah tampilan dari rangkaian arduino agar dapat memonitoring suhu ruangan sekaligus dapat terhubung dengan smartphone.

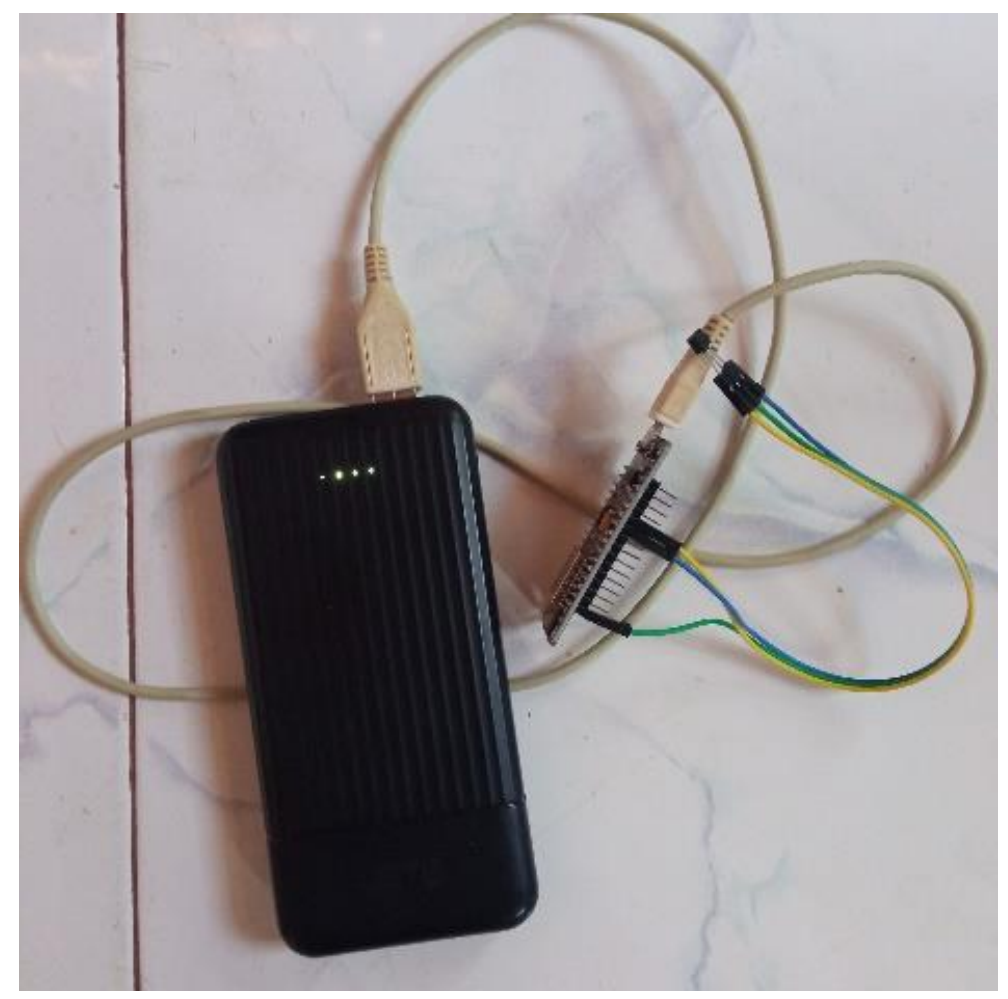

Gambar 3. Rangkaian Arduino

\subsubsection{Gambar Simulasi Alat}

a) Berikut adalah proses menghidupkan alat Monitoring Suhu dengan daya power bank, yang dapat dilihat pada gambar 4 : 


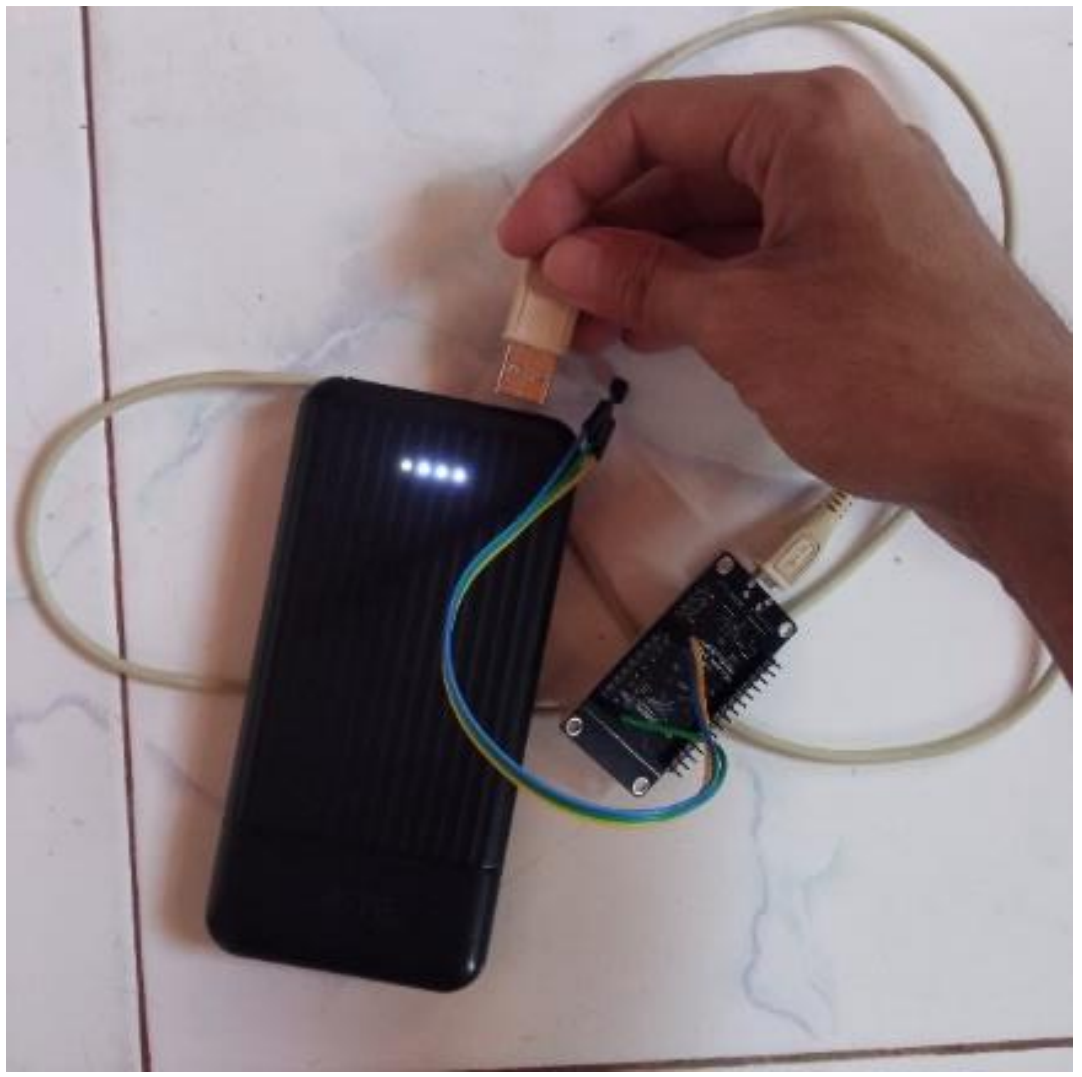

Gambar 4. Menyalakan NodeMCU dengan daya power bank

b) Proses menghubungkan alat Monitoring Suhu dengan jaringan hotspot smartphone, yang dapat dilihat pada gambar 5 :

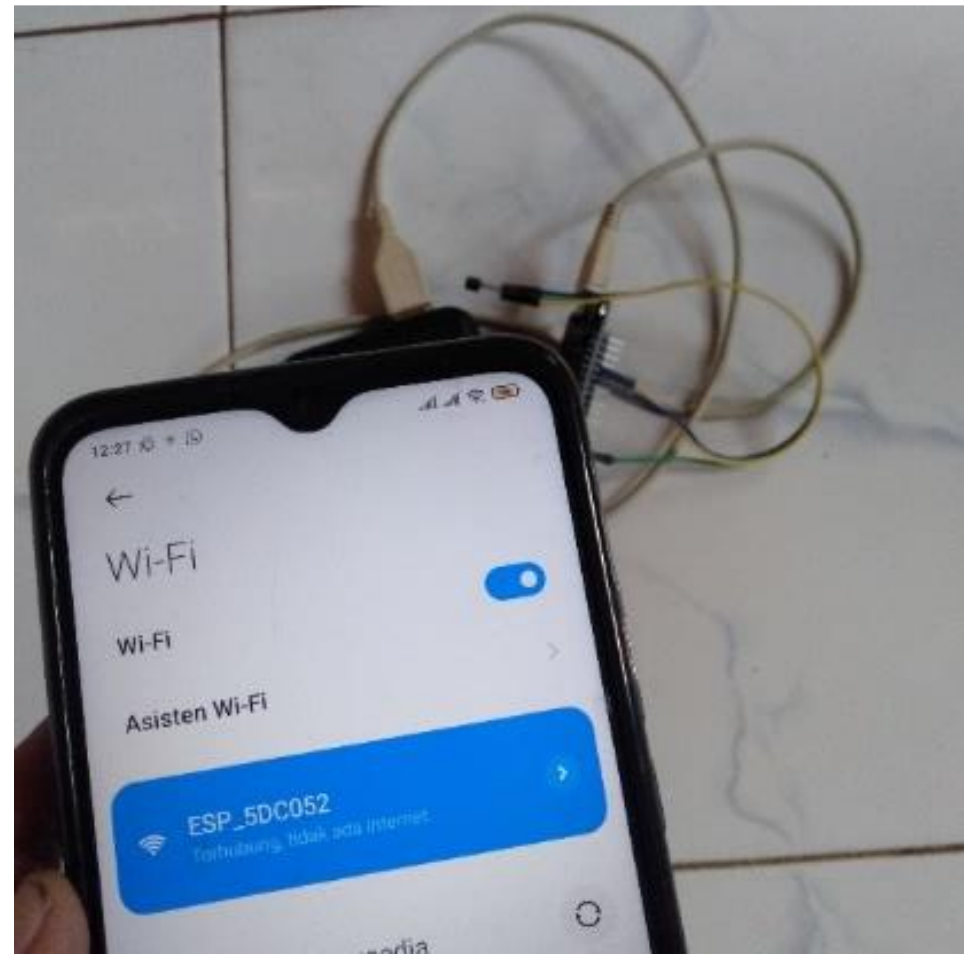

Gambar 5. Menghubungkan NoceMCU dengan smartphone melalui koneksi hotspot 
c) Mengakses aplikasi monitoring suhu untuk melihat hasil pengukuran suhu, yang dapat dilihat pada gambar 6 :

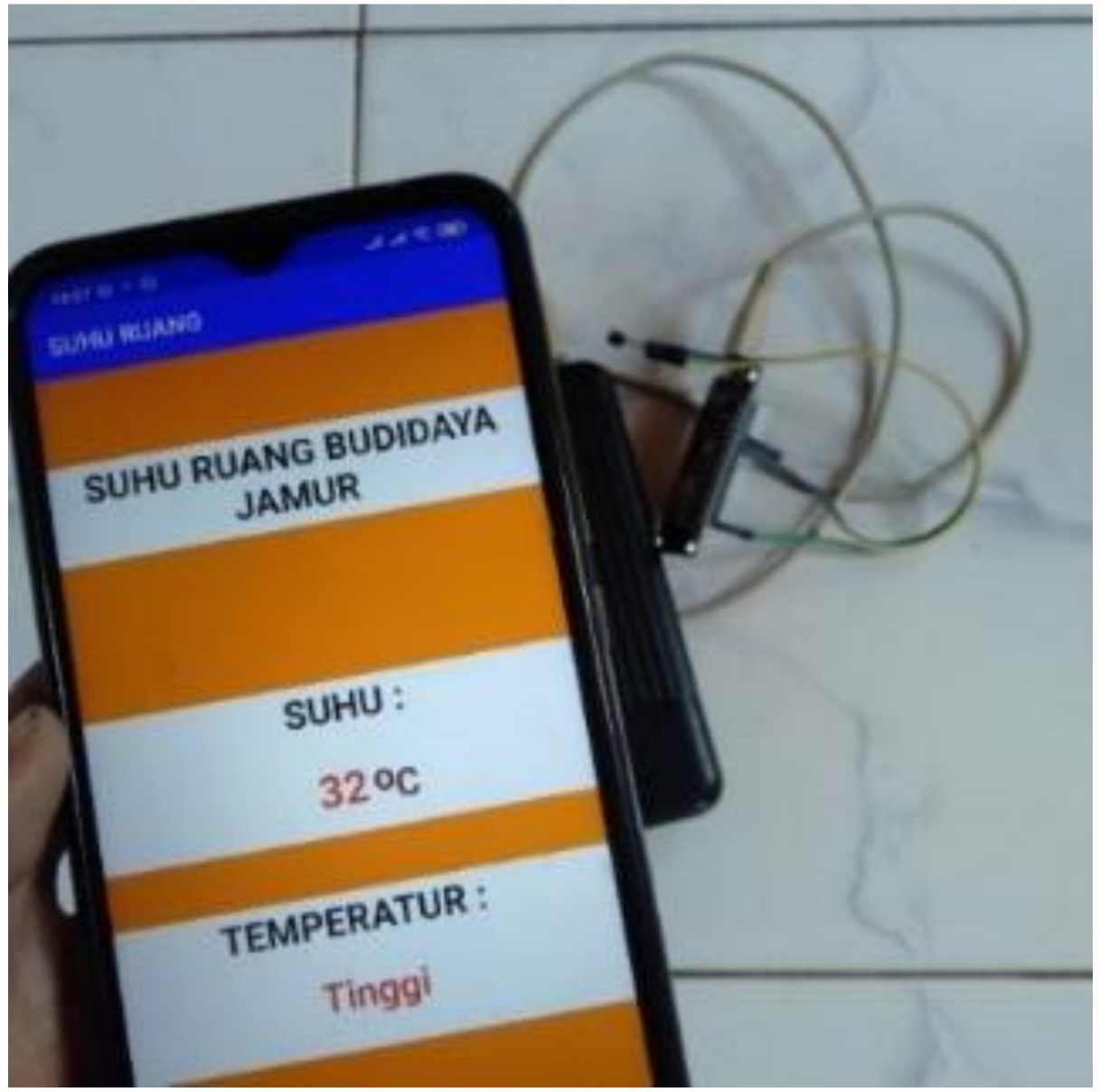

Gambar 6. Membuka Aplikasi Monitoring Suhu Ruang

\section{KESIMPULAN}

Dari hasil uji coba yang dilakukan maka dapat disimpulkan bahwa sistem ini cukup efektif pada beberapa kondisi tertentu dan dapat memonitoring suhu ruang. Tetapi sistem ini juga memiliki beberapa kekurangan di mana untuk menjalankannya dibutuhkan listrik dan koneksi jaringan yang cukup stabil, keterbatasan deteksi sensor, serta butuh pengembangan agar dapat berjalan lebih baik lagi.

\section{SARAN}

Sistem ini sebenarnya dapat dikembangkan lagi menjadi lebih baik dengan menggunakan alat yang lebih canggih. Sistem ini juga dapat digunakan di ruangan apapun. Demikian saran dari penulis semoga saran tersebut dapat dijadikan sebagai bahan masukan yang dapat bermanfaat bagi orang lain. 


\section{DAFTAR PUSTAKA}

[1] Siti Monalisa and Boni Kurniadi, "Sistem Informasi Monitoring Perkembangan Skripsi dengan Reminder System untuk Mahasiswa," Digital Zone: Jurnal Teknologi Informasi dan Komunikasi, vol. 10, no. 1, pp. 23-32, 2019, doi: 10.31849/digitalzone.v10i1.2340.

[2] Z. S. Puranti, W. Yuwono, and R. Asmara, "Monitoring Proyek Akhir Mahasiswa Berbasis Android Pada Sistem Informasi Manajemen PENS," Technomedia Journal, vol. 6, no. 2, pp. 138-151, 2022.

[3] R. Rosyid and M. A. W. Prasetyo, "Robot Peraga 12 Gerakan Pengaturan Lalu Lintas Berbasis Arduino Mega 2560," Technomedia Journal, vol. 5, no. 2 Februari, pp. 193205, 2021.

[4] N. Sany, G. K. Hanum, and S. Sutrisno, "Perancangan Aplikasi Pendeteksi Kebersihan Air Dalam Tangki Air Menggunakan Smartphone Berbasis IoT," Technomedia Journal, vol. 4, no. 2 Februari, pp. 235-247, 2020.

[5] I. Y. Syas and F. A. Rakhmadi, "Prototipe Sistem Monitoring Serta Kendali Suhu Dan Kelembapan Ruangan Budidaya Jamur Tiram Putih Menggunakan Sensor Dht22 Dan Mikrokontroler Nodemcu," Sunan Kalijaga Journal of Physics, vol. 1, no. 1, pp. 7-13, 2019.

[6] N. Kadek et al., "Rancang bangun aplikasi mobile siska berbasis android," vol. 1, no. 2, pp. 100-107, 2018.

[7] N. H. L. D. NURUL HIDAYATI LUSITA DEWI, "Prototype smart home dengan modul nodemcu esp8266 berbasis internet of things (iot)." UNIVERSITAS ISLAM MAJAPAHIT MOJOKERTO, 2019.

[8] A. Tandilintin, A. P. Candra, and G. S. Adji, "Perancangan Aplikasi Project Monitoring Pada PT Cyber Solution Berbasis Web," Innovative Creative and Information Technology, vol. 5, no. 1, pp. 68-76, 2019.

[9] I. Salamah, L. Lindawati, and H. Y. Sitompul, "Aplikasi Bimbingan Tugas Akhir Menggunakan Notifikasi Berbasis Android," Jurnal Media Informatika Budidarma, vol. 3, no. 3, p. 232, 2019, doi: 10.30865/mib.v3i3.1216.

[10] W. A. Purnomo, G. Ali, and D. N. Pratami, "ANALISIS DAN PERANCANGAN SISTEM E-CUTI PEGAWAI BANK BERBASIS WEB,” Simtika, vol. 3, no. 3, pp. 9$18,2020$.

[11] S. Herawati, "Rancang Bangun Sistem Monitoring Suhu Ruangan Bagian Pembukuan 
Berbasis Web Meggunakan Mikrokontroler Arduino Uno R3," Jurnal Teknologi Informasi dan Komunikasi, vol. 13, no. 1, pp. 18-33, 2018.

[12] P. Giashinta, "Alat pengatur suhu kelembaban dan monitoring masa panen pada budidaya jamur tiram berbasis arduino uno," Universitas Negeri Yogyakarta, 2018.

[13] D. R. Soulthan, "PERANCANGAN SMART MONITORING SYSTEM PADA PEMBUDIDAYAAN JAMUR TIRAM BERBASIS PEMROGRAMAN ARDUINO DAN LABVIEW," 2018.

[14] R. A. Wijaya, S. W. L. W. Lestari, and M. Mardiono, "Rancang Bangun Alat Monitoring Suhu dan Kelembaban Pada Alat Baby Incubator Berbasis Internet Of Things,” Jurnal Teknologi, vol. 6, no. 1, p. 52, 2018.

[15] D. I. Putri, "PERANCANGAN SISTEM INFORMASI MONITORING PERPUSTAKAAN UNTUK MENINGKATKAN KUALITAS PERPUSTAKAAN PADA SMA NEGERI 9 KOTA TANGERANG,” 2019. 